\title{
Investigation of helical strut attached vena cava filter hemodynamic performance
}

\author{
Selcuk Selimli \\ Department of Energy Systems Engineering, Karabuk University, Karabuk, 78050, Turkey. \\ Corresponding Author: selcukselimli@karabuk.edu.tr
}

Submitted :06/03/2020

Revised : :21/02/2021

Accepted : 28/02/2021

\begin{abstract}
Hemodynamic performance of the Celect Platinum vena cava filter and the revised forms of it with helical flow inducer strut were studied with computational fluid dynamic software Ansys Fluent 18. The central velocity and shear stress increased but overall flow disturbance has been observed minimal level. Central velocity increases to $9.72 \%$ with Celect filter, by the single helical flow inducer strut the rate reaches to $14.69 \%$, and with doubled form it reaches to $19.73 \%$. The filter surface shear rate increases to $8.29 \%$ with the single helical flow inducer strut and increases $13.31 \%$ with doubled attachment. Increased velocity and shear stress on the filter may eliminate short term thrombus build-up problems by breaking the big size particulates with the high shearing forces. The new struts may also contribute to the ability of the filter to capture smaller clots, as well as to dissolve them from being bigger. Shear stress in the vein wall increases approximately $6.63 \%$ with the filter placement. It raises to $8.06 \%$ and $9.45 \%$ with single and double helical flow inducer strut attachment. Increased vein wall shear may reduce the recirculation and clotting in the vein wall and it may prevent the accumulation of clots. The increased shear stress on the filter may cause the migration problem, design improvements can minimize this risk. Helical flow inducer strut attachment can cause efficacy increase, and the flow are normalized.
\end{abstract}

Keywords: Non-newtonian fluid; Pulsating flow; Unsteady flow; Vena cava filter; Wall shear stress.

\section{INTRODUCTION}

Inferior vena cava (IVC) filters are used to inhibit the reaching of blood clots to the heart and lungs by the implementation of interventional radiologists or vascular surgeons. Small size clots circulate in the vein system do not create any problems, but larger ones moving from the struts and lower part of the abdomen to lung cause the breathing problems, chest pain, irregular blood flow and conjunctions of the fibres. The large size clots sometimes accumulate at the wall of the strut veins and are called deep vein thrombosis (DVT). In time the DVT breaks away and freely flows into to heart and lung. It causes the blockage of the blood flow in the arterial system to the lung. This sudden blockage is called pulmonary embolism (PE) and it can be deadly. The filters were designed to prevent embolism by collecting the clots in case of the placement in the large veins. Vena cava filters were first introduced and used in 1998 to reduce the risk of pulmonary embolism (Shah et al., 2016). Inferior vena cava filters can be evaluated in two groups as two permanent and retrievable (Ghatan \& Ryu, 2016). The availability of retrievable filters has altered the practice patterns for the vena cava filters ( DeYoung \& Minocha, 2016). Despite the wide use of IVC filters to prevent pulmonary embolism. There are very few prospective controlled studies that have not yet 
been sufficiently conclusive on the effectiveness and safety of IVC filters (Bikdeli et al., 2017). The global economic value of the vena cava filter market exceeded $\$ 430$ million in 2016 (Bikdeli et al., 2017). Recently, IVC filters that are physically attached or tethered to a wire or central venous catheter have been introduced as devices that can be implanted for up to 30 days. Evolutionary changes to IVC filter designs and delivery systems have been ongoing. Methods of theoretical modelling and computational fluid dynamics (CFD) based design optimization is a convenient method to develop vena cava filters, theoretical support for the optimization of applicability and minimize the hemodynamic disruption (Singer et al., 2010), (Wei et al., 2019). The effectiveness of an IVC filter is significantly affected by its hemodynamic characteristics (Couch et al., 2000). Very large shear stresses may activate platelets and cause thrombosis, which can completely block blood flow (Ku, 1997). In the arterial circulation, higher shear stresses due to increased blood flow contribute to the dilution of certain procoagulant molecules, thereby preventing insoluble fibrin formation (Kroll et al., 1996). VCF occlusion after filter deployment continues to be a challenge even in the modern era of medicine (Chen et al., 2021). Local hemodynamic close to the filter plays an important role to determine filter efficacy. Low wall shear stress and recirculation zones support thrombin and fibrin accumulation and cause thrombosis (Ferdous et al., 2013). Stagnant and/or recirculating flow regions are potentially thrombogenic regions with low shear stress (Singer et al., 2009). The clogging of the vena cava filters in a short time in the application and the negativities caused by the flow pattern have been evaluated in many medical studies, but a limited number of engineering studies have sought a solution. Contributing to the literature is the motivation of this study. In this computational study for this purpose, the effect of modification of Celect Platinum inferior vena cava filter with helical flow inducer strut on blood flow hemodynamic properties and filter performance was evaluated.

\section{Governing Equations}

Blood shear exhibits thinning behavior and is known as a non-Newtonian fluid. The Carreau model differs from other models (eg, Power-law) because it captures the asymptotic behaviour of shear-thinning fluids with the best approach at both low and high shear rates, making the Carreau model popular in modelling blood flow (Aycock at al. 2016) . Carreau model in Equation (1) describes the dependence of viscosity to the shear rate:

$\mu(\dot{\gamma})=\mu_{\infty}+\left(\mu_{0}-\mu_{\infty}\right)\left(1+(\lambda \dot{\gamma})^{2}\right)^{\frac{n-1}{2}}$

Time constant $(\lambda=3.313 \mathrm{~s})$, Power-law index $(\mathrm{n}=0.3568)$, zero shear viscosity $\left(\mu_{0}=0.056 \mathrm{~kg} / \mathrm{ms}\right)$, infinite shear viscosity $\left(\mu_{\infty}=0.00345 \mathrm{~kg} / \mathrm{ms}\right)$ are taken from ref. (Cho \& Kensey, 1991)] .

For a non-Newtonian fluid, $\mu(\dot{\gamma})$ which is related to the second invariant of the rate-of-deformation tensor $\mathrm{D}$ in Equation (2) is defined as in ref. (Kabinejadian et al., 2012):

$\dot{\gamma}=\sqrt{\frac{1}{2} D: D}$

For the non-Newtonian simulations, the Reynolds number (Re) in Equation (3) was calculated as in ref. (Aycock at al. 2016):

$R e=\frac{\rho u D_{c}}{\mu_{c, n-N}}$ 
In eq. (3), $\rho$ is the blood density, $D_{c}$ is the characteristic diameter, $\mu_{c, n-N}$ is the viscosity computed by the Carreau model. Flow simulation based on incompressible Navier-Stokes Equation (4) and continuity Equation (5) equations are defined as in ref. (Kutev et al., 2015):

$\rho \frac{\partial \vec{u}}{\partial t}+\rho(\vec{u} \cdot \nabla) \vec{u}+\nabla P-\nabla \tau=0$

$\nabla \cdot \vec{u}=0$

$u$ is the flow velocity, $\rho$ is the density, $\tau$ represents stress tensor, and $P$ typifies the pressure. Stress tensor in Equation (6) and the rate of deformation tensor (D) in Equation (7) investigated in the form as is given below in ref. (Nadau \& Sequeira, 2007)and (Tian et al., 2013):

$\tau=2 \mu \dot{\gamma} D$

$D=\frac{1}{2}\left(\nabla u+\nabla u^{T}\right)$

\section{MATERIAL AND METHODS}

With the development of IVC filter design, normalization of arterial blood flow and reduction of common complications associated with filters are very important in practice. In this context, computational numerical analysis study was carried out to determine the effect of geometric improvements on the Celect Platinum filter model, which was revised to normalize the blood flow and increase the filter performance. The unclogged Celect filter models which are modified with the attachment of helical flow inducer geometric struts have been studied. The thread pitch of the helical struts is $9 \mathrm{~mm}$. A single helical flow inducer strut is attached to the first model, and the other with a double. Vein that has $164 \mathrm{~mm}$ length and $22 \mathrm{~mm}$ diameter, and Celect filters that is $55 \mathrm{~mm}$ length and $0.5 \mathrm{~mm}$ strut diameter and attached with single and double helical flow inducer have been designed in Solidworks. The blood body is modelled by ANSYS Design Modeler and meshed with the ANSYS Meshing. The blood body and the filter models studied are shown in Fig. 1.

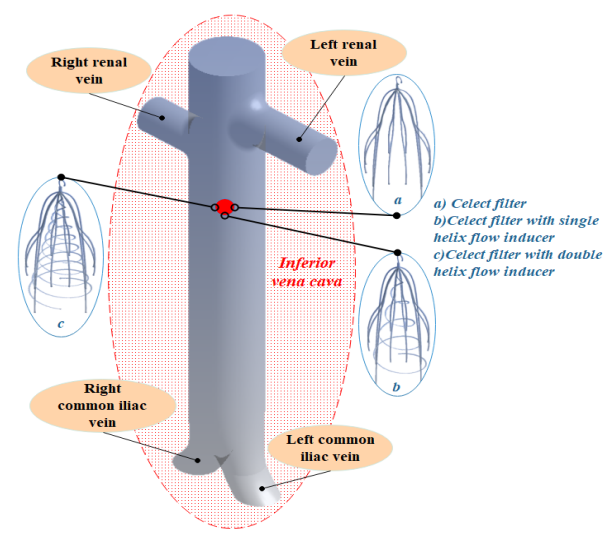

Figure 1. Inferior vena cava model. 
The modelled vena cava blood body was numerically assessed to the grid independence and converge tests. In order to minimize the discretization error in simulation analysis the optimum mesh size selection is prior (Aziz et al., 2013). The solution method and boundary conditions of the numerical study were determined as given in Table 1.

Table 1. Method and boundary conditions of the study.

\begin{tabular}{|c|c|}
\hline Solver & Pressure-Based, Transient \\
\hline Formulation scheme & Implicit, Simple \\
\hline Viscous model & Laminar \\
\hline Material & Blood, Non-Newtonian, Homogeneous, Incompressible \\
\hline Viscosity model & Carreau \\
\hline Inlet boundary & Pulsating velocity, (given in Fig. 2) \\
\hline Outlet boundary & Zero gage pressure outlet \\
\hline Temperature (K) & 309 \\
\hline Converge criteria & $1 \mathrm{e}-5$ \\
\hline
\end{tabular}

The properties of blood which include the density $\left(1050 \mathrm{~kg} / \mathrm{m}^{3}\right)$ were obtained by accounting the nature of blood pulsatile flow (Pandey et al., 2020). The blood flow in the arterial system is pulsating and the waveform of the flow was applied as in ref. (Chong et al., 2017), (Fraser et al., 2008), (Rizzo et al., 1992) based on the user-defined function (UDF) form to the vena cava model. The pulsating blood flow rate is illustrated in Fig. 2.

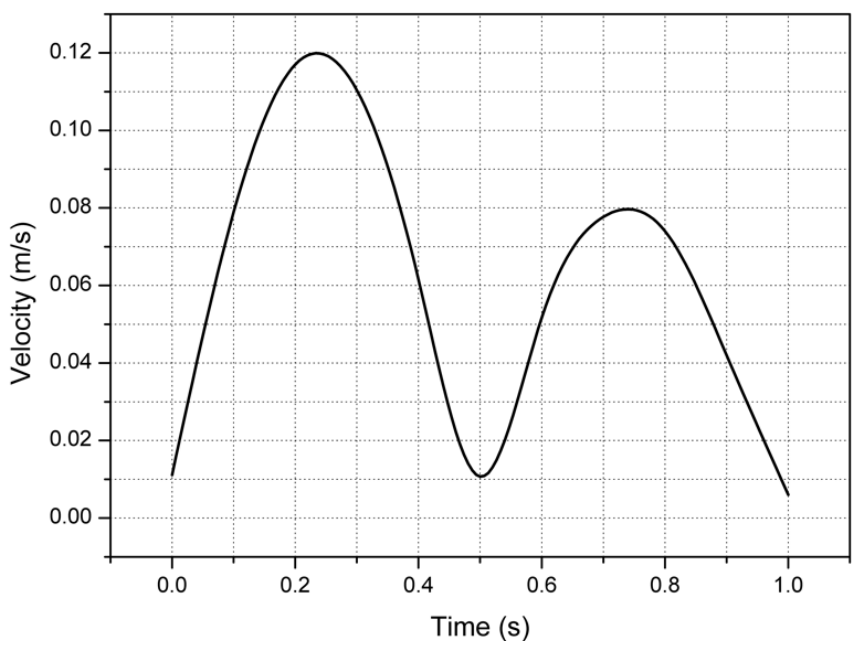

Figure 2. Pulsating inlet velocity.

The results of the grid independency study have been performed with models with different numbers of element are visualized and compared in Fig. 3. 


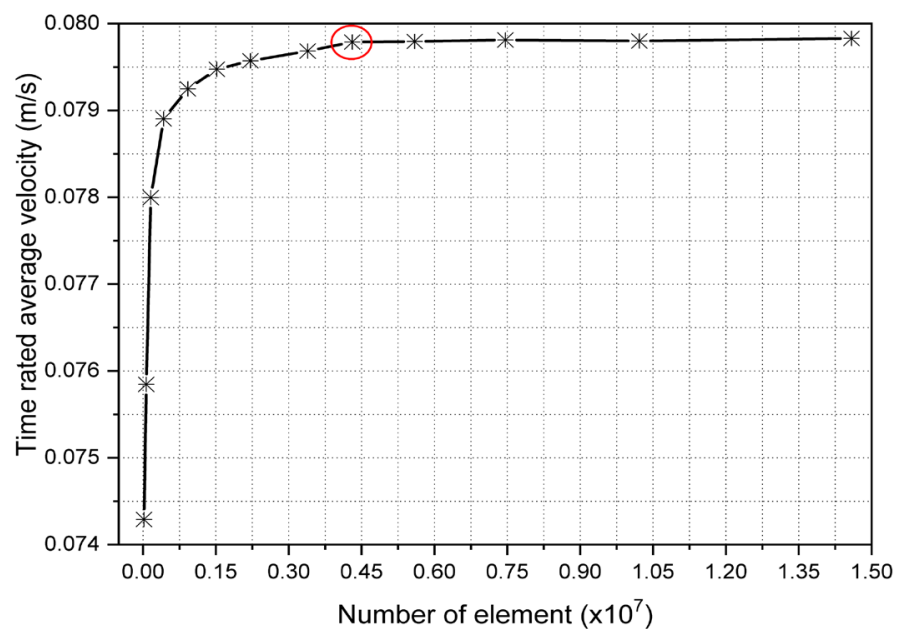

Figure 3. Time rated average velocity for the different number of grids.

High quality grid converge result is typically for values of less than $1 \%$ (Longest \& Vinchurkar, 2007). As a result of the mesh study, it has been determined that a deviation rate of $0.01 \%$ can be obtained with the 4,309,400 element model. Also, skewness and orthogonal quality mesh metrics spectrum are 0.47 and 0.98 . Considering that this deviation rate was sufficient for the study, this cell number was chosen for the analysed models. The decrease in parametric deviation and the normalization of values are shown in Fig. 3.

\section{RESULTS AND DISCUSSION}

Physical changes in the flow by revised Celect filter with helical flow inducer struts examined by computational fluid dynamics method. The long-term advantages and disadvantages of the helical flow inducer attachments were assessed with a hemodynamic perspective. The change in blood flow velocity in peak systole time $(t=0.2 \mathrm{~s})$ in at the central region of the inferior vena cava was visualized in Fig. 4.

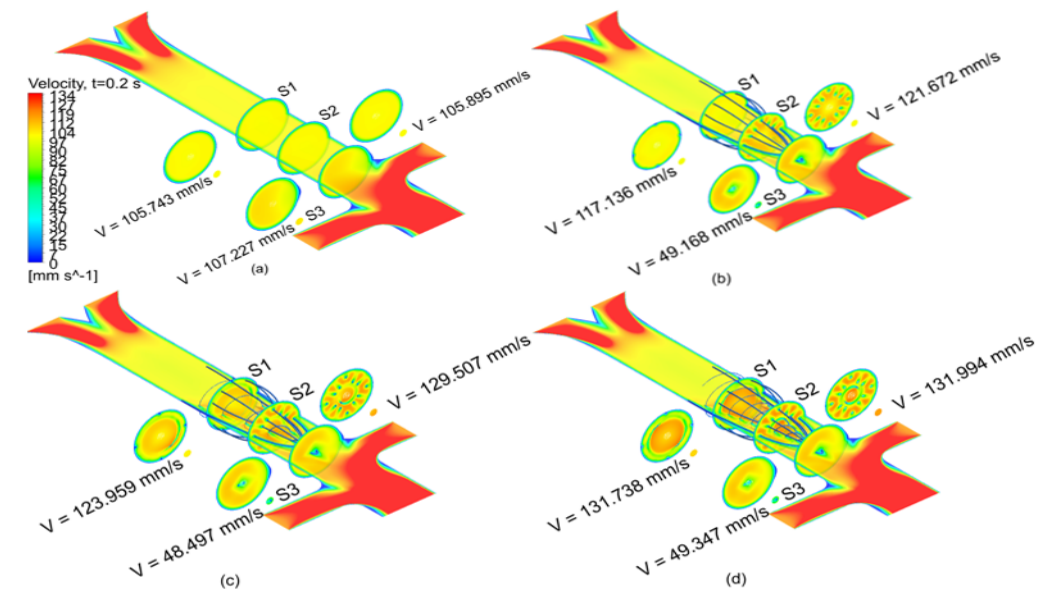

Figure 4. The central average velocity of the blood body, a) without filter, b) with Celect filter, c) Celect filter with single helical flow inducer d) Celect filter with double-helical flow inducer. 
The filter effect on blood flow is presented in Figure 4. The central velocity at S1, S2 and S3 sectional cross sections of the flow body increases with the filter effect, this increase is strengthened by the helical inductor. In ref. (Craven et al., 2018) reported that high-velocity region in the centre of the IVC lumen. Increased central velocity leads the directing of the clots to the low-pressure flow central region and eliminates the accumulation of them in the vein wall. The increased velocity can also help break large sized clots hitting the filter at higher velocity into smaller ones and increase the clogging time of the filter. Helical flow inducer attached filter models have also increased the central velocity more and the positive effect of the filter was enhanced. The increase of the central velocity is approximately about $9.72 \%$ by the Celect filter usage at the $\mathrm{S} 1$ which is the catching location of filter. This increase reaches to $14.69 \%$ by single helical strut attachment and with double helical strut attachment reaches to $19.73 \%$. The higher wall shear stress and flow velocities on vena cava filters may cause a decreased risk of hemostasis (Wang \& Singer, 2010). The flow is normalized and the average velocity at S1, S2 and S3 were presented in Fig.5.

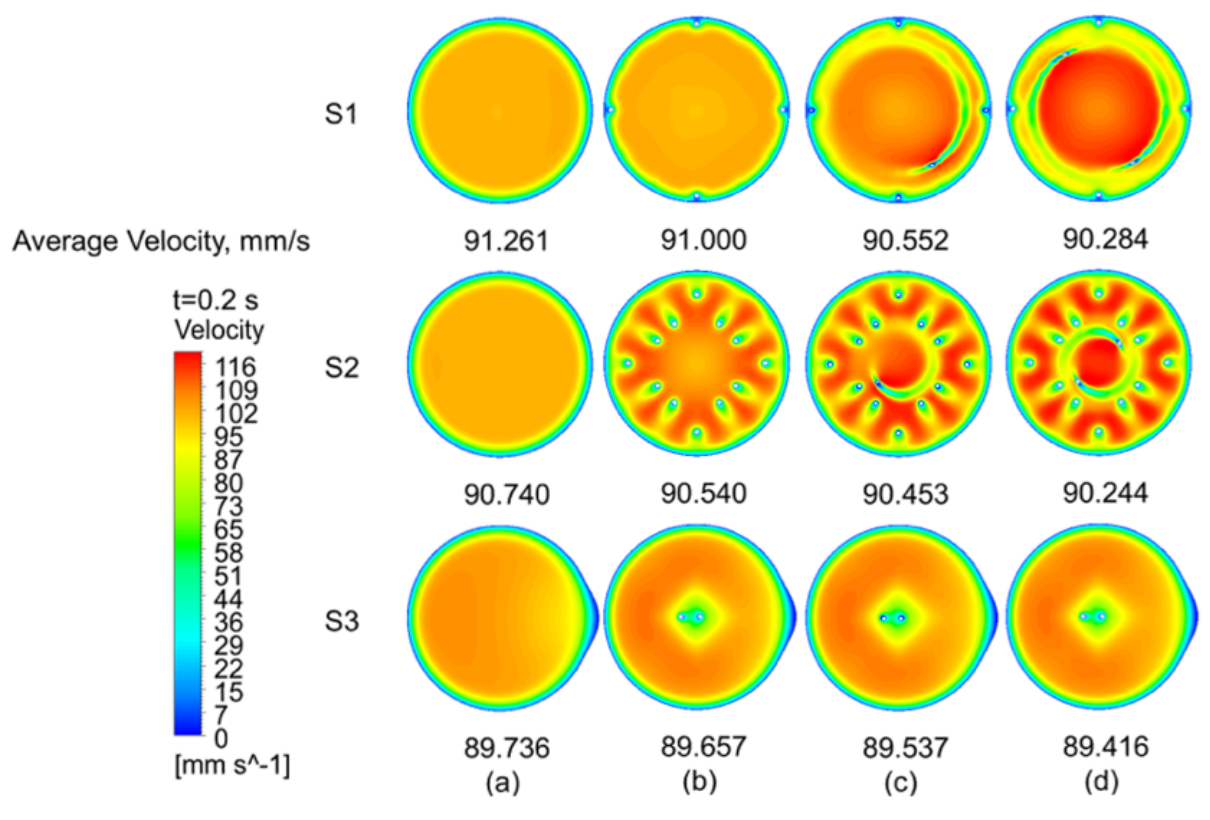

Figure 5. Local velocity variation, a) without filter, b) with Celect filter,

c) Celect filter with single helical flow inducer d) Celect filter with double-helical flow inducer.

Helical flow inducer attachment to the vena cava filter decreased the resistance to the flow at the near-wall region and flow normalized. While a significant speed increase was observed in the filter centre, a slight decrease was observed in the average velocity at S1, S2 and S3. Helical flow inducers supported this decrease. The increased filter surface area has significantly increased filter capture performance while creating minimal disturbance to the flow. Larger filter area may increase clot-trapping efficacy (Couch et al., 2000). The shear stress variation on the filter by the modification was visualized in Fig. 6 . 


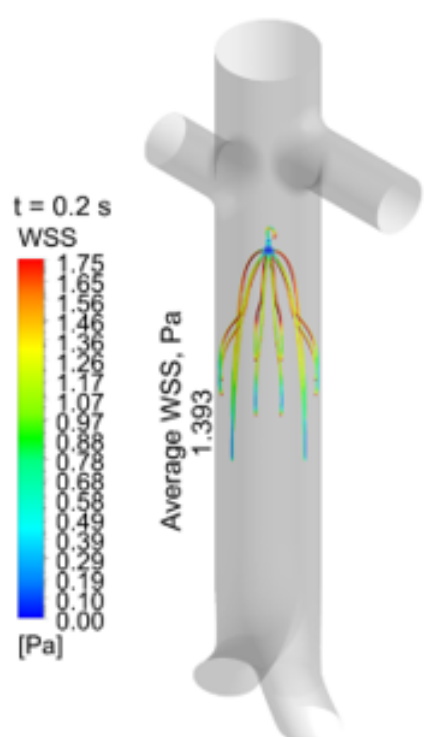

(a)

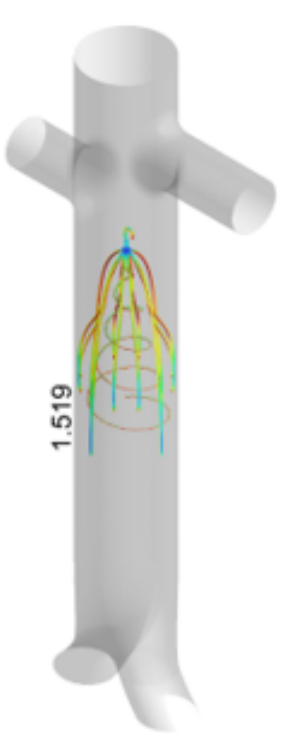

(b)

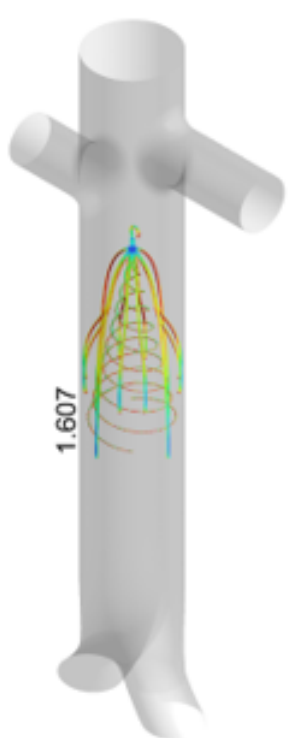

(c)

Figure 6. Filter wall shear stress, a) with Celect filter, b) Celect filter with single helical flow inducer c) Celect filter with double-helical flow inducer.

Shear stress on the filter wall increases approximately $8.29 \%$ by single helical flow inducer strut and $13.31 \%$ by the double-helical flow inducer strut attachment. Increased shear on the filter has advantages and disadvantages due to the in vitro studies. The shearing forces may cause mechanical lysis of the trapped clot, dissolute them and thus provides the continuity of flow through the inferior vena cava (Couch et al., 1997). At low shear rates, red blood cells tend to form linear arrays of stacked cells or three-dimensional aggregates (Litvinov \& Weisel, 2017). Risk of filter migration may cause by increased shear stress could be minimized by the design enhancements. The shear stress on the vena cava wall has been illustrated in Fig. 7.

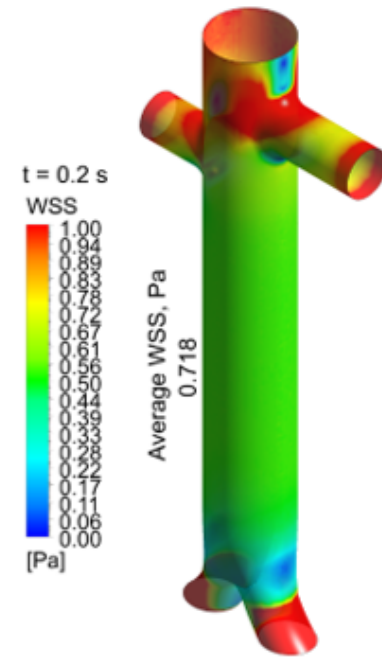

(a)

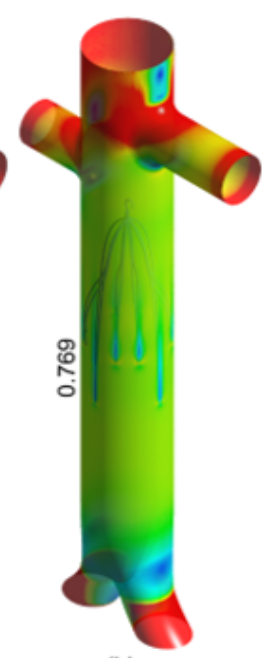

(b)

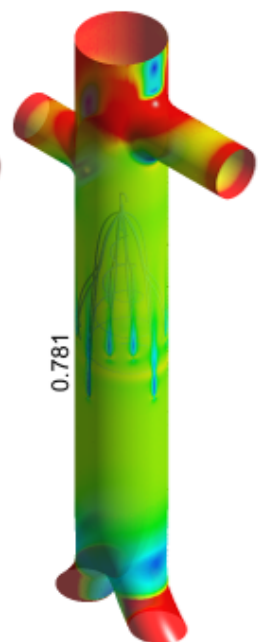

(c)

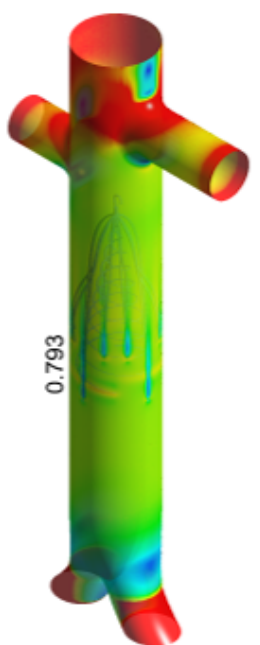

(d)

Figure 7. The vena cava wall shear stress, a) without filter, b) with Celect filter, c) Celect filter with single helical flow inducer d) Celect filter with double-helical flow inducer. 
The vein wall shear stress increases $6.63 \%$ with the filter placement, reaching $8.06 \%$ with the single helical flow inducer and $9.45 \%$ with the doubled form as seen in Fig. 7. Low shear stress and the recirculation flow are seeing as the cause of the accumulation of particulate structures (Gulan et al., 2017), (Couch et al., 2000). Increased vein wall shear may contribute to the prolongation of the blockage. The variation of blood viscosity because of non-Newtonian characteristics is given in Fig. 8.

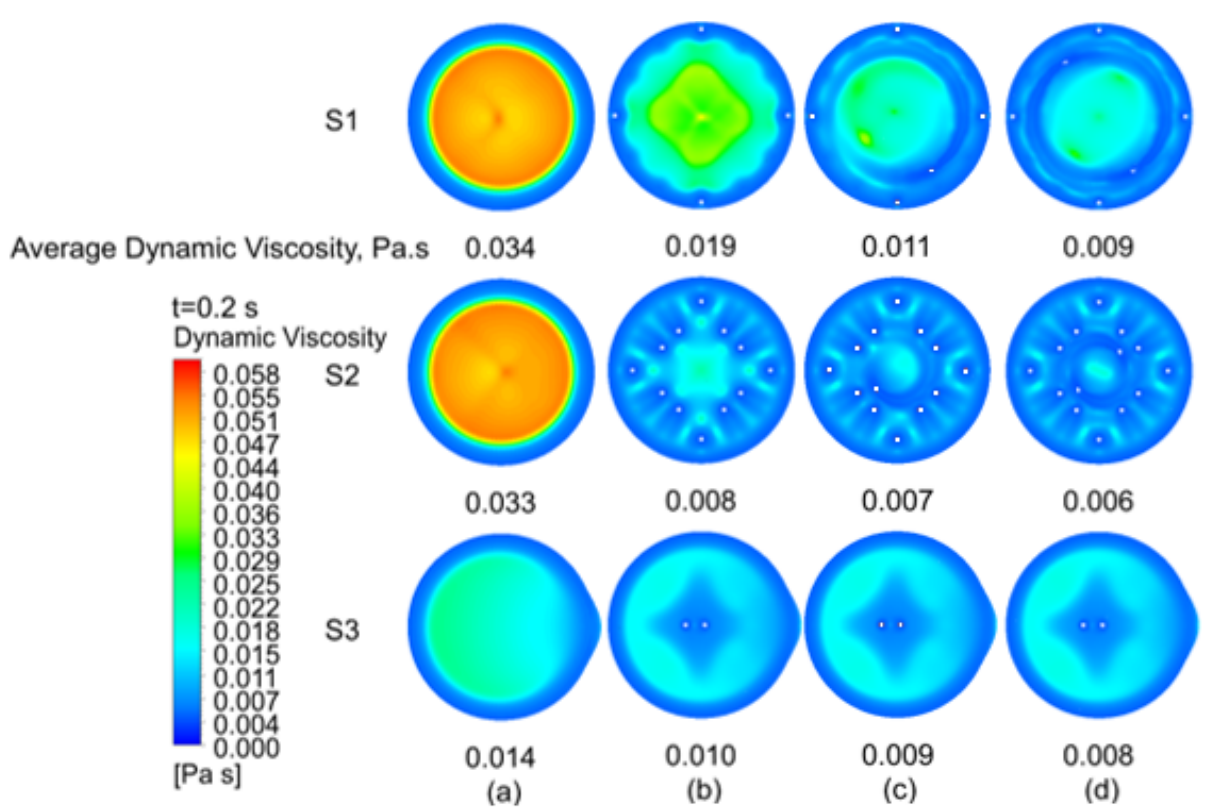

Figure 8. Variation of viscosity, a) without filter, b) with Celect filter,

c) Celect filter with single helical flow inducer d) Celect filter with double-helical flow inducer.

Central and the overall viscosity declined by the increase of velocity and shear stress. Change of viscosity at S1, $\mathrm{S} 2$ and S3 are examined, it is seen that the maximum change in viscosity was formed in the flow body where the double-helical flow inducer filter applied. The maximum change of the viscosity was seen in the S3 and minimum change is at S2. The blood viscosity largely increases as velocity and shear rate decreases (Yeom et al., 2014).Low shear stress leads to increased viscosity of large aggregates, but with the increase of shear rate, the aggregate breaks down and the viscosity decreases to a constant rate (Wagner et al., 2013).

\section{CONCLUSION}

Vena cava filter occlusion in the short term, hemodynamic problems, filter efficiency, and migration of the filter are among the topics of the near future studies. Researchers who are from the field of medicine and engineering believe that the hemodynamic performance of vena cava filters can be improved by structural improvements. The aim of the present study is to evaluate the performance of the existing Celect Platinum vena cava filter with the addition of helical flow inducer struts. The filter revision with helical flow inducer strut attachment has been studied computationally and compared with the current filter design. The result is that the filter placed in the vein increases the central velocity approximately $9.72 \%$, by the single helical flow inducer strut the rate reaches to $14.69 \%$, and with doubled form it reaches to $19.73 \%$. Shear stress on the filter has been increased approximately $8.29 \%$ with the single helical flow inducer strut and increases $13.31 \%$ with doubled attachment. The shearing on the vein wall has been increased $6.63 \%$ with the filter placement. It raises to $8.06 \%$ and $9.45 \%$ with single and double helical flow inducer strut attachment. This study results showed that the hemodynamic performance of the vena cava filter may 
enhance filter efficacy. The blockage period of the filter can be extended by the increased blood flow central velocity and shear stress. The addition of the more filter material and surface area did not increase considerably the resistance against the flow. Increased surface area and shear stress enhances the clot catching ability of the filter and prolong the time of clogging. Helical flow inducer also normalizes the flow regime.

\section{REFERENCES}

Aycock, K.I., Campbell, R.L., Lynch, F.C., Manning, K.B., \& Craven, B.A. 2016. The Importance of Hemorheology and Patient Anatomy on the Hemodynamics in the Inferior Vena Cava. Ann Biomed Eng 44(12):3568-82.

Aziz, M.A., Abdullah, M.Z., Khor, C.Y., \& Ani, F.C. 2013. Influence of pin offset in PCB through-hole during wave soldering process: CFD modeling approach. International Communications in Heat and Mass Transfer 48:116-23.

Bikdeli, B., Chatterjee, S., Desai, N.R., Kirtane, A.J., Desai, M.M., Bracken, M.B., Spencer, F.A., Monreal, M., Goldhaber, S.Z., \& Krumholz, H.M. 2017. Inferior Vena Cava Filters to Prevent Pulmonary Embolism: Systematic Review and Meta-Analysis. J Am Coll Cardiol 70(13):1587-97.

Bikdeli, B., Ross, J.S., \& Krumholz, H.M. 2017. Data Desert for Inferior Vena Caval Filters: Limited Evidence, Supervision, and Research. JAMA Cardiol 2(1):3-4.

Chen, Y., Xu, Z., Deng, X., Yang, S., Tan, W., Fan, Y., Han, Y., \& Xing, Y. 2021. Effects of reverse deployment of cone-shaped vena cava filter on improvements in hemodynamic performance in vena cava. BioMed Eng OnLine 20(19):1-15.

Chen, Y., Zhang, P., Deng, X., Fan, Y., Xing, Y., \& Xing, N. 2017. Improvement of hemodynamic performance using novel helical flow vena cava filter design. Sci Rep 7:40724.

Cho, Y.I. \& Kensey, K.R. 1991. Effects of the non-Newtonian viscosity of blood on flows in a diseased arterial vessel. Part 1: Steady flows. Biorheology 28(3-4):241-62.

Chong, A.Y., Doyle, B.J., Jansen, S., Ponosh, S., Cisonni, J., \& Sun, Z. 2017. Blood flow velocity prediction in aortoiliac stent grafts using computational fluid dynamics and Taguchi method. Comput Biol Med 84:23546.

Couch, G.G., Johnston, K.W., \& Ojha, M. 2000. An invitro comparison of the hemodynamics of two inferior vena cava filters. Journal of Vascular Surgery 31(3):539-49.

Couch, G.G., Kim, H., \& Ojha, M. 1997. In vitro assessment of the hemodynamic effects of partial occlusion in a vena cava filter. Journal of Vascular Surgery 25(4):663-72.

Craven, B.A., Aycock, K.I., \& Manning, K.B. 2018. Steady Flow in a Patient-Averaged Inferior Vena CavaPart II: Computational Fluid Dynamics Verification and Validation. Cardiovascular Engineering and Technology 9(4):654-73.

DeYoung, E. \& Minocha, J. 2016. Inferior Vena Cava Filters: Guidelines, Best Practice, and Expanding Indications. Semin Intervent Radiol 33(2):65-70.

Ferdous, J., Ghaly, M., Fatematuzzahan, \& Shazly, T. 2013. In Silico Evaluation of Local Hemodynamics Following Vena Cava Filter Deployment. Proceedings of the 2013 COMSOL Conference, Boston.

Fraser, K.H., Meagher, S., Blake, J.R., Easson, W.J., \& Hoskins, P.R. 2008. Characterization of an Abdominal Aortic Velocity Waveform in Patients with Abdominal Aortic Aneurysm. Ultrasound in Medicine \& Biology 34(1):73-80. 
Ghatan, C.E. \& Ryu, R.K. 2016. Permanent versus Retrievable Inferior Vena Cava Filters: Rethinking the "OneFilter-for-All" Approach to Mechanical Thromboembolic Prophylaxis. Semin Intervent Radiol 33(2):75-8.

Gulan, U., Saguner, A., Akdis, D., Gotschy, A., Manka, R., Brunckhorst, C., Holzner, M., \& Duru, F. 2017. Investigation of Atrial Vortices Using a Novel Right Heart Model and Possible Implications for Atrial Thrombus Formation. Sci Rep 7(1):1-10.

Kabinejadian, F. \& Ghista, D.N. 2012. Compliant model of a coupled sequential coronary arterial bypass graft: Effects of vessel wall elasticity and non-Newtonian rheology on blood flow regime and hemodynamic parameters distribution. Medical Engineering \& Physics 34(7):860-72.

Kroll, M.H., Hellums, J.D., McIntire, L.V., Schafer, A.I., \& Moake, J.L. 1996. Platelets and shear stress. Blood 88(5):1525-41.

Ku, D.N. 1997. Blood Flow in Arteries. Annu. Rev. Fluid Mech. 29(1):399-434.

Kutev, N., Tabakova, S., \& Radev, S. 2015. Approximation of the oscillatory blood flow using the Carreau viscosity model. 2015 International Conference on Mechanics - Seventh Polyakhov's Reading. Saint Petersburg State University, Russia.

Litvinov, R.I. \& Weisel, J.W. 2017. Role of red blood cells in hemostasis and thrombosis. ISBT Sci Ser 12(1):176-83.

Longest, P.W. \& Vinchurkar, S. 2007. Effects of mesh style and grid convergence on particle deposition in bifurcating airway models with comparisons to experimental data. Medical Engineering \& Physics 29(3):350-66.

Nadau, L. \& Sequeira, A. 2007. Numerical simulations of shear dependent viscoelastic flows with a combined finite element-finite volume method. Computers \& Mathematics with Applications 53(3):547-68.

Pandey, R, Kumar, M., \& Srivastav, V.K. 2020. Numerical studies of blood flow in left coronary model. Recent Advances in Computer Science and Communications 13(6): 1228-1238.

Rizzo, G., Arduini, D., \& Romanini, C. 1992. Inferior vena cava flow velocity waveforms inappropriate- and small-for-gestational-age fetuses. American Journal of Obstetrics and Gynecology 166(4):1271-80.

Shah, R., Turk, A., Rahim, B., Arafat, W., Nazeef, M., \& Mattison, R.J. 2016. Inferior Vena Cava Filter Appropriate Use and Retrieval. Blood 128(22):5912.

Singer, M.A., Henshaw, W.D., \& Wang, S.L. 2009. Computational modeling of blood flow in the TrapEase inferior vena cava filter. J Vasc Interv Radiol 20(6):799-805.

Singer, M.A., Wang, S.L., \& Diachin, D.P. 2010. Design optimization of vena cava filters: an application to dual filtration devices. J Biomech Eng 132(10):101006.

Tian, F.B., Zhu, L., Fok, P.W., \& Lu, X.Y. 2013. Simulation of a pulsatile non-Newtonian flow past a stenosed 2D artery with atherosclerosis. Comput Biol Med 43(9):1098-113.

Wagner, C., Steffen, P., \& Svetina, S. 2013. Aggregation of red blood cells: From rouleaux to clot formation. Comptes Rendus Physique 14(6):459-69.

Wang, S.L. \& Singer, M.A. 2010. Toward an Optimal Position for Inferior Vena Cava Filters: Computational Modeling of the Impact of Renal Vein Inflow with Celect and TrapEase Filters. Journal of Vascular and Interventional Radiology 21(3):367-374.

Wei, S., Xing, Y., Ma, H., Li, R., Song, C., \& Tong, Z. 2019. Numerical simulation of a new horizontal spray tower for sintering flue gas desulfurization. Journal of Engg. Research 7(4):1-17.

Yeom, E., Kang, Y.J., \& Lee, S.J. 2014. Changes in velocity profile according to blood viscosity in a microchannel. Biomicrofluidics 8(3):34110. 